\title{
A CONSTRUÇÃO DO ETHOS EM MARÍLIA DE DIRCEU DE TOMÁS ANTÔNIO GONZAGA
}

\section{THE CONSTRUCTION OF ETHOS IN MARÍLIA DE DIRCEU OF TOMÁS ANTÔNIO GONZAGA}

Recebido: 11/04/2021

Aprovado: $21 / 06 / 2021$

Publicado: $30 / 07 / 2021$

DOI: $10.18817 /$ rlj.v5i01.2571

\author{
Jaciel Ribeiro Rodrigues ${ }^{1}$ \\ Orcid ID: https://orcid.org/0000-0002-2036-451X \\ Layana Kelly Pereira de Holanda 2 \\ Orcid ID: https://orcid.org/0000-0001-8323-7000
}

Resumo: O presente artigo propõe-se a destacar a construção de ethos da personagem Dirceu, na obra Marília de Dirceu, de Tomás Antônio Gonzaga. Para isso, a pesquisa sustenta-se na Análise do Discurso Francesa, especificamente, a teoria de Maingueneau (2008). O estudo advém da problemática: Como se apresenta a construção do ethos de Dirceu na obra Marília de Dirceu? Analisou-se, a Lira I da parte I, como forma de recorte da pesquisa. A Lira tem como temática: apresentar Dirceu, um homem tido como honrando e respeitado, por todos por meio de suas posses e do seu caráter a confiança de seu destinatário, no caso Marília. O eu-lírico constrói uma imagem de si exemplar, em um discurso que inspira confiança, enfatizando sua humildade, simplicidade e o amor verdadeiro. A metodologia partiu de uma pesquisa bibliográfica, interpretativa e analítica, de cunho qualitativo, tendo como base os teóricos, além do mencionado acima, Amossy (2008) e Eggs (2008), entre outros. Observou-se que a Lira I da parte I, corresponde a elementos de corporalidade que implica no modo de atuação no espaço social do sujeito.

Palavras-chave: Discurso. Construção de ethos. Marília de Dirceu. Tomás Antônio Gonzaga.

Abstract: The present article proposes to highline the construction of the ethos from the character Dirceu, in the literature work Marilia De Dirceu of Tomás Antônio Gonzaga. For that the research sustain itself in the French Speech Analyzes, specifically, in the Maingueneau's (2008) theory. The study is come of the problematic: how the construction of the ethos in Dirceu on the work Marilia de Dirceu constructs itself? It was analyzed the Lira I of the first part, as a form of researcher cutout. The lira has as thematic: to prove in was of posses and character that Dirceu is an honorable and respected man, gaining the trust of its recipient, Marilia. The I-lyric build an image of an exemplar itself, in a speech that inspire confidence, emphasizing in his humility, simplicity and true love. The methodologic left from a bibliography, interpretative and analytic research of qualitative nature, having as base the theorists among the others mentioned above, Amossy (2008) and Eggs (2008), and others. It was observed that the Lira I from the first part correspond it to elements of corporeality that implies in the method of acting in the social space of the subject.

\footnotetext{
1 Possui graduação em Letras Português/Inglês pela Universidade Anhanguera Uniderp e Letras Português/Literatura pela Universidade Estadual do Maranhão - UEMA. Especialista em Ensino de Língua Portuguesa e Literatura Brasileira pelo Instituto de Ensino Superior Franciscano - IESF. Pósgraduando em Literatura e Ensino pela - UEMANET. E-mail: jacielr6@gmail.com

${ }^{2}$ Possui Graduação em Letras Português pela Universidade Estadual do Piauí - UESPI. Especialista em Linguística e Ensino pela Universidade Estadual do Piauí - UESPI. Especialista em Docência para a Educação Profissional pelo Serviço Nacional de Aprendizagem Comercial - SENAC-SP. Mestra em Letras pela Universidade Federal do Piauí - UFPI, área de concentração em Estudos de Linguagem (Linguística) e linha de pesquisa: Descrição do Português na perspectiva enunciativa da teoria das Operações Predicativas e Enunciativas. É membro do grupo de Estudo das Teorias Operativas Enunciativas - GETOE na UFPI de Teresina. Pesquisadora na área da Enunciação e Ensino de Gramática. E-mail: layana_holanda@hotmail.com
} 
Keywords: Discourse. Construction of ethos. Marília de Dirceu. Tomás Antônio Gonzaga.

\section{Introdução}

Esta pesquisa visa destacar o ethos da personagem Dirceu, na obra poética Marília de Dirceu, de Tomás Antônio Gonzaga, autor mineiro, influenciado pelo movimento iluminista, foi um dos primeiros homens a lutar a favor da Independência do Brasil, em parcerias com outros autores. Condenado à prisão, Gonzaga, é exilado do país cuja vida é desfeita, deixando em Vila Rica, cidade onde morava, trabalho, amigos e o seu grande amor, Maria Doroteia Joaquina de Seixas, a sua inspiração da obra Marília de Dirceu.

A obra, em análise, estabelece relação com as experiências de vida do autor e, como destaca Candido (2009), o poema de lirismo amoroso constitui-se de um roteiro de uma experiência concreta. Ou seja, o livro representa em várias partes, um desabafo da vida do autor, pois ele coloca em evidência seu amor por Maria Doroteia Joaquina de Seixas, planos para um futuro juntos e sua vida na prisão. $\mathrm{Na}$ figura do pastor Dirceu, Gonzaga confidencia suas experiências pessoais, exaltando a imagem de si e da amada, "a gentil pastora”, Marília e, assim, Gonzaga contempla sua dor e paixão por meio das Liras.

No que diz respeito à construção do ethos para Maingueneau (2008), o ethos consiste em o sujeito provar de forma digna o seu caráter, causando uma boa impressão ao seu destinatário, além de exaltar a imagem de si no discurso. Dessa forma, o ethos também estabelece uma relação com o espaço em que o próprio sujeito se encontra, visto que ele recorre das experiências sócio-históricos para concluir seu discurso. Essa ação para Maingueneau (2008) é considerada corporalidade $^{3}$ (espaço social) e ocorre quando o locutor se movimenta no espaço representando socialmente.

Nessa perspectiva, o estudo mostra as marcas que a personagem Dirceu utiliza para construir a imagem de si, usando expressões que colaboram para provar a sua conduta, enquanto homem de confiança. Portanto, é observado, no poema em análise, o discurso a partir do caráter (os traços psicológicos) e a relação de

\footnotetext{
${ }^{3}$ Quanto à "corporalidade", ela é associada a uma compleição corporal, mas também a uma forma de vestir-se e de mover-se no espaço social. (MAINGUENAU, 1995).
} 
corporalidade da personagem, assim, proporcionando um processo de comunicação entre os interlocutores e para a construção do ethos.

Para alcançar os objetivos da pesquisa, realizou-se uma pesquisa bibliográfica, interpretativa e analítica, de cunho qualitativo, bem como a escolha da Lira I da parte I. Para destacar o ethos da personagem Dirceu, analisou-se os estudos e perspectivas metodológicas analíticas, sobretudo, de Maingueneau (2008).

\section{A construção do ethos}

Os elementos que consistem em apresentar a imagem de si no discurso, correspondem ao ethos, cujo processo é observar a formação e a construção da comunicação, num determinado material escrito (no caso do artigo corresponde a Lira I da parte I, da obra Marília de Dirceu, de Tomás Antônio Gonzaga), que representa a imagem do enunciador, no caso Dirceu, para inspirar ao seu destinatário confiança e ganhar credibilidade pela formação do seu caráter.

Nesse sentido, o ethos discursivo implica na construção do autorretrato do sujeito, com intenção de valorizar o caráter e as virtudes do enunciador. Amossy (2008, p.9) diz que: "todo ato de tomar a palavra implica a construção de uma imagem de si". [...]. Isto é, o sujeito procura revelar informações de si, que implica na valorização de sua personalidade e ações morais, constrói-se como um ser digno de confiança, que provoca um posicionamento persuasivo em seu destinatário.

O discurso, portanto, é produzido a partir de uma determinada posição social do sujeito, traçado com as experiências pessoais, tornando revelador o caráter do sujeito, com a intenção enunciativa de tornar evidentes as vozes presentes no texto. Isso ocorre, devido à escolha das palavras na construção do discurso, uma vez que essa seleção corrobora para o sujeito edificar sua imagem e facilitar a produção e a aceitação do interpretante, assim, exercer influência em seu destinatário, como destaca Gouvêa (2013):

[...] Nessa perspectiva, tornar a palavra é atividade cotidiana do ser humano e, através desse ato, é possível estabelecer um contrato de comunicação com o sujeito interpretante que construirá, conscientemente ou não, determinada imagem do sujeito enunciador. (GOUVÊA, 2013. p. 153). 
Portanto, a palavra apresenta efeito de mudança, permitindo interação em um ato de comunicação entre o enunciador e o seu interpretante, produzindo efeito de sentido. Nesse processo interativo, o sujeito exalta sua personalidade, construindo sua imagem no discurso que produz. A construção do ethos é representada por meio do comportamento que acentua no processo de corporalidade, isto é, um conjunto de representação social do sujeito, que segundo Maingueneau (1995, p. 139): "é associada a uma compleição do corpo do fiador, inseparável de uma maneira de se vestir e se movimentar no espaço social", ou seja, ocorre quando revela as concepções socioculturais do sujeito.

Nessa perspectiva, o caráter construído no discurso, apoia-se em um conjunto de representações sociais que permitem ao sujeito arquitetar sua imagem. Conforme as experiências de mundo e a partir dos estereótipos culturais associados ao comportamento, Maingueneau (1995, p. 139) afirma que "o caráter corresponde a um feixe de traços psicológicos. [...] são apenas estereótipos específicos de uma época, de um lugar, que a literatura contribui para validar e nos quais se apoia" [...]. Esse processo colabora para o sujeito plasmar suas características e a expôs no discurso que produz.

Dessa forma, torna-se explícito que o ethos discursivo edifica-se da relação entre o caráter e a corporalidade, desempenhando um papel social do sujeito cuja ação é colaborar para o processo de interação, pois todo discurso é destinado a um interlocutor. As características psíquicas (traços psicológicos) cooperam para que o sujeito possa modelar seu discurso para que o outro, no ato de influenciar, crie para si uma imagem digna de confiança e respeito, ou seja, tornar visível seu caráter.

Nessa perspectiva, o ethos é interacional e está centrado na incorporação do eu, um processo discursivo que torna possível a construção da imagem de si, bem como evidenciar seus atributos, com a finalidade de expor suas ideias ao seu destinatário. Para tanto, a construção do ethos, além de provar uma boa impressão tem a capacidade de influenciar um determinado grupo, colocando em primeiro plano as características do sujeito no discurso, como enfatiza Maingueneau (2008):

A prova pelo ethos consiste em causar boa impressão pela forma como se constrói o discurso, a dar uma imagem de si capaz de convencer o auditório, ganhando sua confiança. O destinatário deve, então, atribuir certas propriedades à instância que é posta como fonte do acontecimento enunciativo. (MAINGUENEAU, 2008, p 13). 
Observa-se que o ethos tem o propósito de prender a atenção do destinatário, visto que o foco de interesse é ganhar a confiança do interlocutor, pois o discurso é construído a partir da relação de corporalidade e caráter (traços psicológicos), assim, atribuindo certas formas de enunciação. Desse modo, a construção do ethos discursivo está relacionada com o caráter do sujeito falante e a forma como o receptor o vê.

A boa impressão do sujeito enunciador é estratégia essencial para a construção do discurso, uma vez que o locutor exalta a sua própria figura, enfatizando seus traços psicológicos e sócio-históricos. Dessa forma, a construção do ethos está associado à formação discursiva, levando em conta as ideologias que corresponde a uma determinada cena que se inscreve no discurso e que cria marcas e as sustentam. Para Maingueneau (2008), o discurso pressupõe uma cena de enunciação para poder ser enunciado e validar por sua própria enunciação: qualquer discurso pretende instituir a situação de enunciação que o torna pertinente. Enfim, é importante frisar que a construção do ethos dá-se a partir da cena de enunciação que permite mostrar no discurso os aspectos sócio-históricos e os traços psicológicos, tornando-se evidente o caráter e o espaço social do sujeito, causando uma boa imagem ao seu destinatário. A seguir, vê-se mais aprofundado, pontos sobre o autor e obra analisada.

\section{O autor e a obra Marília Dirceu}

Nascido no Porto, em Portugal, no ano de 1744, Tomás Antônio Gonzaga, era filho de um magistrado brasileiro e de uma portuguesa. Cursou Direito na faculdade de Direito, em Coimbra. Em 1782, após o término de seus estudos veio para o Brasil, onde exerceu o cargo de ouvidor, em Vila Rica. Em 1768, escreveu uma tese para habilitar ao cargo de professor. A tese intitulada Direito Natural é considerada sua primeira obra, dedicada ao marquês de Pombal, que era muito amigo de seu pai.

Escreveu Cartas Chilenas, obra cuja finalidade é satirizar a administração do Governador Luís da Cunha Mendes. Segundo Bosi (2015, p. 74-75), [...] "Gonzaga as escreve no intuito de satirizar seu desafeto político, o Governador Luís da Cunha Meneses, que nelas aparece sob o disfarce de Fanfarrão Minésio". As Cartas Chilenas são direcionadas ao seu amigo Doroteu, e a obra é uma produção de 
críticas destrutivas dos desmandos administrativos do governo, ridicularizado por suas arbitrariedades.

Em Vila Rica, por volta do ano 1782, Tomás Antônio Gonzaga, corteja Maria Doroteia Joaquina de Seixas, jovem de dezessete anos, ficando-se noivos. Com a presença de Maria Doroteia, o autor inicia a primeira parte da obra Marília de Dirceu, mas o confronto com o poder político, ele é preso e seu noivado destruído, deixando para traz o amor de sua vida. Conformado com seu futuro sem a presença da noiva ao seu lado, Gonzaga, continua a segunda parte do livro, na prisão.

Gonzaga participou do grupo mineiro, que tinha ideias contrárias do poder político. Revolucionário e influenciado pelo movimento lluminista, foi um dos primeiros homens a lutar pela Independência do Brasil, atuou junto com outros autores do grupo que tratavam de questões sobre a liberdade do país. Foi preso e condenado ao degredo e exilado do país. Em primeira instância, Gonzaga, permaneceu preso na llha de Cobras, sobre ordem política, parte para Moçambique, onde constrói uma nova vida ao lado de Juliana de Sousa Mascarenhas, mulher rica e analfabeta, casam-se e tem dois filhos. Em 1910, morre e logo após sua esposa, deixando os filhos.

A obra, Marília de Dirceu, é composta de três partes que representam a vida do autor. O livro descreve uma história de amor, destruído pela força política cuja primeira parte é contemplada pela a presença da amada em sua vida. $O$ sentimentalismo, a tranquilidade e a sutileza da linguagem torna a obra triunfante, apresentando versos livres, brancos, diversificados, decassílabos, tetrassílabos, redondilhas maior e menor, bem como os aspectos bucólicos.

A segunda parte, escrita na prisão, apresenta uma poesia mais forte, pois o poeta narra seus momentos de angústia: "estou no inferno, estou, Marília bela, e numa coisa só é mais humano a minha dura estrela" [...] (GONZAGA, 2013. p. 99). Com o pseudônimo de Dirceu, Gonzaga, coloca-se a imagem de um homem aprisionado e apaixonado, com saudade de sua amada. Dessa forma, a obra é uma representação bibliográfica da vida de Gonzaga, como afirma Candido (2000), a poesia de Gonzaga aparenta ser um fenômeno vivo e autêntico por brotar de uma experiência humana e palpitante.

Marília de Dirceu narra o amor puro e fiel de um homem apaixonado e seguro de seu amor, por consequência do destino é separado de sua amada. Destruído e apaixonado, Gonzaga, dá luz ao livro, que contempla as fases e situações de sua 
vida: o amor, a saudade de Maria Doroteia e suas experiências na prisão. Diante dessas experiências, Tomás Antônio Gonzaga, desabafa seu amor e suas dores, debruçando sobre o individualismo, assim, consegue dar à obra elementos vivos, como afirma Candido (2000. p.109) "o poema de lirismo amoroso tecido à volta duma experiência concreta (...) ou o roteiro de uma personalidade" [...]. Deixando nítido as paixões e a destruição de sua vida amorosa em versos, capazes de transmitir a sinceridade e o afeto de um homem emanado de sentimento.

A obra é dedicada à eterna Maria Doroteia Joaquina de Seixas, a famosa Marília. Sua presença nas Liras é bastante visível, e fundamental para a estruturação dos versos, neles contidos a grandeza do amor, planos para o futuro e a perfeição de Marília. Dirceu idealiza a imagem da mulher amada com dedicação e perfeição, exaltando-a, conforme os versos: "Só no céu achar-se podem tais belezas como aquelas, que Marília tem nos olhos, que tem nas faces belas" (GONZAGA, 2013, p. 31). Percebe-se que a personagem, descreve fisicamente a beleza de Marília, ele cria a figura de uma mulher bela e pura com muitos atributos.

\section{A construção do ethos em Marília de Dirceu}

Para analisar a construção do ethos, selecionou-se a Lira I da parte I da obra Marília de Dirceu, nela o eu-lírico valoriza sua imagem e apresenta ao seu interlocutor suas posses, mostrando-se um homem de caráter. Percebe-se que o discurso de Dirceu é centrado no seu modo de vida, pois ele tem a intenção de gerar confiança, sobretudo, valorizar seu caráter moral enquanto homem apaixonado, isso ocorre porque a personagem pretende convencer seu destinatário.

Na ótica de Maingueneau (2008, p. 13), "a prova do ethos consiste em causar uma boa impressão por meio do modo como se constrói o discurso, em dar de si uma imagem capaz de convencer o auditório ao ganhar sua confiança”. No caso da Lira, a forma como ele constrói o discurso evidencia os elementos destacados por Maingueneau: a boa impressão, convencimento e confiança. Na primeira estrofe da Lira, pode-se perceber a presença desses elementos: 
Tenho próprio casal, e nele assisto; dá-me vinho, legume, fruta, azeite; das brancas ovelhinhas tiro o leite, e mais as finas lãs, de que me visto.

Graças, Marília bela,

Graças à minha Estrela! (GONZAGA, 2013, p.19).

O primeiro ponto discursivo de Dirceu, na estrofe, é apresentar-se como proprietário de alguns dotes, e que não depende de ninguém, que pode viver sem nenhuma preocupação, bem como dar uma boa vida a sua amada. O eu-lírico está em uma boa condição social, mostrando não ser inferior às outras pessoas, valorizando suas posses e atribuindo-se boas qualidades, ele se expõe, dessa maneira para causar uma boa impressão à Marília e, sobretudo, construir sua imagem e provar que a ama.

A imagem de si no discurso, revelada pelo eu-lírico, visa enfatizar o caráter moral do sujeito, uma vez que essa imagem colabora para o destinatário observar os elementos mostrados pelo locutor. Dessa forma, Dirceu destaca que além de possuir dotes, é respeitado pelas outras pessoas: "os pastores, que habitam este monte, respeitam o poder do meu cajado" (GONZAGA, p. 14). Nota-se que o eu-lírico se apresenta como um homem de boa conduta, com posses que a sustentam, além de ser respeitado.

Então, pode-se observar que o eu-lírico constrói a imagem de si mesmo, exaltando seu caráter e suas posses. Esses elementos são fundamentais para a construção do discurso, uma vez que os traços psicológicos servem de argumentos para se destacar no processo discursivo. A Lira analisada é refletida a partir de um determinado lugar, nesse caso, o campo, a vida bucólica longe da área urbana, assim, o eu-lírico se apresenta conforme o espaço que se encontra.

Dessa forma, a corporalidade é reconhecida no texto quando a personagem Dirceu menciona os produtos que são típicos do campo: o gado, o azeite, a fruta, a ovelhinha, tirar o leite, vocabulários de referências socioculturais que ele mesmo possui, pois o eu-lírico veste-se das representações sociais como afirma Maingueneau (2008). Como se pode ver, Dirceu articula seus argumentos de posses para poder mostrar à Marília que é um homem conceituado, preparado para a vida, de bom caráter e que a ama.

Para tanto, o eu-lírico se mostra como um homem apaixonado e sente admiração pela mulher amada, sobretudo, que é a pessoa perfeita para se casarem 
e viverem juntos, cuja situação financeira é suficiente para o futuro dos dois. A exaltação da mulher amada permite expressar o verdadeiro amor que Dirceu sente por Marília, embora tenha todas as qualidades, porém ele afirma que nada vale ter tudo isso se não tem o seu amor, conforme apresenta a estrofe:

\author{
Mas tendo tantos dotes de ventura, \\ só apreço Ihes dou, gentil Pastora, \\ depois que o teu afeto me segura \\ que queres do que tenho ser Senhora. \\ É bom, minha Marília, é bom ser dono \\ de um rebanho, que cubra monte e prado; \\ porém, gentil pastora, o teu agrado \\ vale mais que um rebanho e mais que um trono. \\ Graças, Marília bela, \\ Graças à minha Estrela! (GONZAGA, 2013, p. 19).
}

Depreende-se nesses argumentos apresentado por Dirceu, a exaltação do poder do seu amor, sobretudo, mostrar uma boa impressão ao seu interlocutor. $\mathrm{Na}$ questão, o ethos de Dirceu é de um homem apaixonado que está disposto a tudo pelo o amor de Marília. Sendo que a sua estratégia de boa impressão consistia em afirmar que tudo que possuía não teria sentido, se ela não estiver ao seu lado e corresponder seu amor: "é bom, minha Marília, é bom ser dono de um rebanho, que cubra monte e prado; porém, gentil pastora, o teu agrado vale mais que um rebanho e mais que um trono" (GONZAGA, 2013, p. 19). E, assim, conseguir atingir o seu ponto principal, convencer a mulher amada de aceitar seu amor.

Para Maingueneau (2008), o ethos é o processo interativo que tem influência sobre o outro e, ao mesmo tempo, uma ação do comportamento que está associada ao ato de comunicação, e integrada numa conjuntura sócio-histórico. Nessa perspectiva, compreende-se que a construção do ethos da personagem Dirceu demostra uma ação de influência sobre Marília, seu caráter e seu comportamento associado à estrutura social em que se encontra, tornando-se um instrumento de convencimento.

Para adquirir a confiança de seu destinatário, o sujeito, busca estratégias para ganhá-la, apostando nas descrições físicas do seu receptor. Dirceu, por sua vez, apresenta que essa estratégia é fundamental para ganhar confiança, e apresentando-se com uma boa impressão, visto que é uma forma de agir e argumentar seu posicionamento diante de tal situação. A estrofe seguinte aponta 
essa estratégia da construção do ethos por exposição dos traços físicos do interlocutor.

\author{
Os teus olhos espalham luz divina, \\ a quem a luz do sol em vão se atreve; \\ papoila ou rosa delicada e fina \\ te cobre as faces, que são cor de neve. \\ Os teus cabelos são uns fios d'ouro; \\ teu lindo corpo bálsamos vapora. \\ Ah! não, não fez o Céu, gentil Pastora, \\ para glória de amor igual Tesouro! \\ Graças, Marília bela, \\ Graças à minha Estrela! (GONZAGA, 2013, p. 20).
}

Ao idealizar a imagem de Marília, Dirceu dá início ao processo interativo, fundamental para a construção do ethos e de influência e, assim, "mobiliza a afetividade do destinatário" (MAINGUENEAU, 2008, p. 14). Ao posicionar-se dessa forma, Dirceu mostra que age e argumenta de forma eficiente, pois de acordo com Eggs (2008), agir e argumentar são estratégias que atingem a soberania moral do debate, e que essas duas faces do ethos proporciona o convencimento pelo discurso. Nesse caso, a intenção do eu-lírico é produzir um efeito positivo, acima de tudo, em seu destinatário.

Assim, os argumentos são construídos a partir de um processo interativo, no qual a personagem aparece numa situação de comunicação, haja vista sua intencionalidade é mostrar-se digno do amor de Marília, bem como causar uma boa imagem. Após a valorização do seu perfil moral, suas posses e seu amor, Dirceu aposta, sobretudo, em um futuro a dois, mostrando a ela o quanto é grande o seu amor, e que a presença um do outro é o suficiente. Assim, o eu-lírico demostra mais uma vez sua humildade e simplicidade, exaltando seu caráter:

Leve-me a sementeira muito embora o rio, sobre os campos levantado; acabe, acabe a peste matador, sem deixar um rês, o nédio gado. Já destes bens, Marília, não preciso nem me cega a paixão, que o mundo arrasta; para viver feliz, Marília, basta que os olhos movas, e me dês um riso.

Graças, Marília bela,

Graças à minha Estrela! (GONZAGA, 2013, p. 20). 
A estrofe indica a valorização do amor, o eu-lírico acredita que as posses e a situação financeira, não é importante, a não que se dividam o amor, como se ver em: "já destes bens, Marília, não preciso nem me cega a paixão, que o mundo arrasta; para viver feliz, Marília, basta" (GONZAGA, 2013, p. 20). A certeza de seu amor por Marília é evidente, ele apresenta sempre como superior e inabalável. A palavra "riso" que finaliza o verso destaca o planejar o futuro deles juntos, momentos de felicidade e tranquilidade que eles dividirão como companheiros. $\mathrm{O}$ tom simples e humilde do eu-lírico, cria uma imagem confiável de sua própria pessoa, assim, propiciando ao destinatário criar uma imagem para si digna de confiança e aceitação.

Para Amossy (2008), o locutor tem a necessidade de se adaptar ao seu auditório, fazer uma imagem dele, e consequentemente construir uma imagem de confiança de sua própria pessoa, em função de suas crenças e valores que ele atribui àqueles que ouvem, ou seja, o sujeito falante conduz um conjunto de valores, se apresenta ao seu destinatário, consequentemente, constrói uma imagem de si, enaltecendo seu caráter capaz de convencer àquele que ouve.

Nesse sentido, Dirceu supervaloriza-se, pois, seus valores, virtudes e intenções são colocados em primeiro plano no discurso, com a finalidade de convencer e gerar credibilidade em sua mulher amada. Enfim, o eu-lírico, constrói a partir de suas intenções, um futuro próspero para os dois, ele arquiteta a cena que juntos irão viver por um longo período, distante dos outros e do local que vivem, assim, constitui um ethos de um homem corajoso e decidido. Isso possível observar na estrofe:

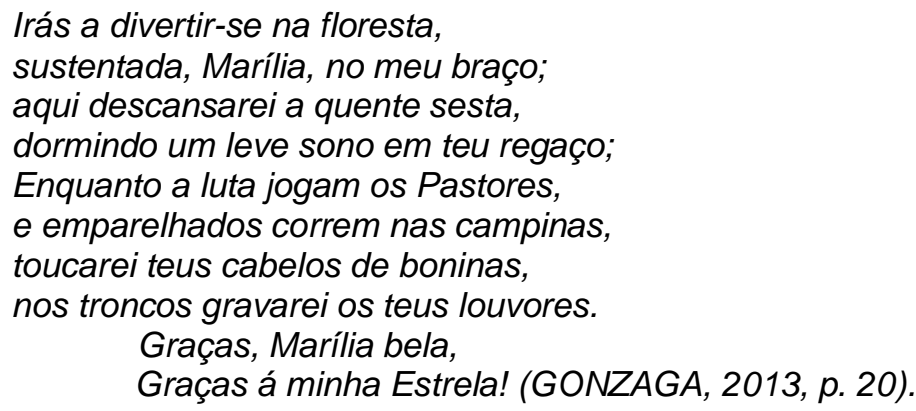

É válido notar que o eu-lírico apresenta à Marília um futuro longe de todos os habitantes do local onde vivem para ele, um ambiente simples e tranquilo é suficiente para viverem juntos eternamente: "irás a divertir-se na floresta, 
sustentada, Marília, no meu braço; aqui descansarei a quente sesta" [...] (GONZAGA, 2013, p. 20). Então, percebe-se que Dirceu articula uma crítica da vida paralela e distinta que levam do lugar onde habitam, enaltecendo a companhia da mulher amada, construindo uma imagem positiva de si mesmo, com isso, concebese a figura do sujeito honrado, digno de confiança.

Assim, tem-se a figura de um sujeito consciente de todo o seu ato, um homem corajoso e honesto que não mede esforço para estar com a mulher amada: "toucarei teus cabelos de boninas, nos troncos gravarei os teus louvores" (GONZAGA, 2013, p. 20). Segundo Eggs (2008), o orador que se mostra com o caráter honesto em seu discurso parecerá mais digno de crédito para seu destinatário. Enfim, a construção de si no discurso realiza um processo de interação entre os interlocutores, visto que a imagem de quem argumenta é essencial para aquele que ouve gerar um conceito positivo do outro.

Nesse sentido, tem-se na Lira I da parte I, a construção da imagem de si da personagem Dirceu, que é constituído por um caráter simples, humilde, digno de confiança e de boas intenções, além de destacar a valorização do seu amor por Marília, exaltando-o, e o planejamento de um futuro próspero ao lado da amada, tudo isso, apresentado para enaltecer a si mesmo. Logo, a Lira I, é um discurso baseado no ethos, segundo Maingueneau (2008), consiste em causar uma boa impressão pela forma como se constrói o discurso, capaz de convencer seu destinatário, uma vez que o eu-lírico se utiliza de argumentos para provar que é uma pessoa de boa moral, além de envolver sua amada em seu discurso, demostrando que possui as melhores intenções.

\section{Considerações finais}

Em Marília de Dirceu, de Tomás Antônio Gonzaga, reúne uma composição de Liras, que estabelece relação com as experiências pessoais do autor, isso porque, as composições são referências de uma vida amorosa, após conhecer Maria Doroteia Joaquina de Seixas, uma jovem que despertou o amor no coração do poeta, concebendo a ela a maior parte das Liras. Sua situação após sua prisão e o exílio para Moçambique, contemplou a composição dos poemas. $\mathrm{Na}$ condição de prisioneiro, Gonzaga compôs uma poesia de dor e sofrimento, pois destaca a angústia de estar preso e distante da mulher amada. 
Dirceu, pastor, trabalha em seu discurso a imagem de si, exaltando-se, apresentando sua condição de homem digno e respeitado ao seu receptor Marília, sua amada. Sendo assim, o eu-lírico tenta provar para a mulher amada seu caráter, sua condição financeira e, sobretudo, seu amor. A Lira, em análise, contemplou as referidas características de Dirceu, através de um discurso convincente, visto que seu objetivo é construir sua própria imagem a partir de sua situação amorosa, tentando convencê-la.

Nesse sentido, a construção do ethos é uma ação comportamental do sujeito, visto que ele se apropria das referências socioculturais e psicológicas. No discurso de Dirceu, comprovou-se o modo como o eu-lírico utilizou-se de um vocabulário bucólico, campestre e rural (florestas, campinas, pastores) para se apresentar ao seu destinatário, fazendo uso da corporalidade e do caráter, aspectos sóciohistóricos e traços psicológicos, que colaboram para a produção do discurso. A imagem de si, no discurso dele, é de um homem de posses, respeitado que tem condições suficientes para se manter bem e viver sem depender de outros.

A Lira I da parte I destacou-se na construção do ethos, por meio de um discurso centrado no caráter da personagem Dirceu. O ethos expõe uma ideia de convencimento, haja vista que sua finalidade é mostrar à Marília que é um homem respeitado, de caráter invejado e de boa intenção, pois seu desejo é construir sua imagem por meio de sua bondade. O planejamento para um futuro a dois, momentos felizes e tranquilos são argumentos que causam uma boa impressão. Sendo assim, Dirceu concebe uma imagem de si digna de honra e que possui melhores intenções em relação à amada.

\section{Referências Bibliográficas}

AMOSSY, R. Imagem de si no discurso: a construção do ethos. $1^{\text {a }}$ ed. São Paulo: Contexto, 2008.

BOSI, A. História concisa da literatura brasileira. 40ª ed. São Paulo: Cultrix, 2015.

CANDIDO, A. Formação da literatura brasileira: momentos decisivos. 6aㅗ ed. Belo Horizonte: Itatiaia, 2000.

EGGS, E. Ethos aristotélico, convicção e pragmática moderna. In. Ruth Amossy (org), Imagem de si no discurso: a construção do ethos. 1a ed. São Paulo: Contexto. p. 29-56, 2008. 
GONZAGA, T. A. Marília de Dirceu. Edição especial. Rio de Janeiro: Nova Fronteira, 2013.

GOUVÊA, M. A. Música de protesto e ethos discursivos no período da ditadura militar: a arte de dizer o proibido. 1. ed. Curitiba: appris, 2013.

MAINGUENEAU, D. A propósito do ethos. In: MOTTA, Ana. Raquel; SALGADO, Luciana. (orgs.). Ethos discursivo. São Paulo: Contexto, 2008. p. 11-29.

. Ethos, cenografia e incorporação. In: Amossy, Ruth. (org.). Imagens de si no discurso: a construção do ethos. $1^{\underline{a}}$ ed. São Paulo: Contexto. p. 6991, 2008.

1995

. O contexto da obra: leitura e crítica. São Paulo: Martins Fontes, 